\title{
Commercial Building Containing Generation Sources: A Technical and Economic Assessment and Its Potential to Participate in Demand Response Programs
}

\author{
Tesoro Elena Del Carpio-Huayllas' ${ }^{1}$, Dorel Soares Ramos ${ }^{1}$, Ricardo Leon Vasquez-Arnez² \\ ${ }^{1}$ Department of Electric Power and Automation Engineering, University of São Paulo, São Paulo, Brazil \\ ${ }^{2}$ FDTE (Foundation for the Technological Development of the Engineering Sciences), São Paulo, Brazil \\ Email: dorelram@usp.br, tesoroelena75@gmail.com, rarnez@fdte.org.br
}

How to cite this paper: Del Carpio-Huayllas, T.E., Ramos, D.S. and Vasquez-Arnez, R.L. (2019) Commercial Building Containing Generation Sources: A Technical and Economic Assessment and Its Potential to Participate in Demand Response Programs. Energy and Power Engineering, 11, 76-91. https://doi.org/10.4236/epe.2019.112005

Received: January 25, 2019

Accepted: February 22, 2019

Published: February 25, 2019

Copyright $\odot 2019$ by author(s) and Scientific Research Publishing Inc. This work is licensed under the Creative Commons Attribution International License (CC BY 4.0).

http://creativecommons.org/licenses/by/4.0/

(c) (i) Open Access

\begin{abstract}
The interest on studying the impact of demand response is growing, especially on residential and commercial buildings which are responsible for a considerable consumption of energy worldwide. Also, it is virtually unquestionable that in most of these buildings there is a waste of energy, mainly electrical and thermal energy. In this context, the establishment of intelligent networks in these buildings, as well as the use of small or even medium-sized renewable sources of power can significantly contribute to the reduction and preservation of power. In this article, the results of the simulations carried out in a specific simulation program to evaluate the benefits brought by the installation of some local sources of power on a commercial building are presented. It is evaluated the impact on some of the economic variables linked to that system as well as compared its greenhouse gas emissions for the conditions with and without the presence of the local generation. It will also evaluate the building's response towards the utility requirements, mainly the possibility to reduce or partially compensate the energy consumed, commonly referred to as Demand Response.
\end{abstract}

\section{Keywords}

Demand Response, Commercial Buildings, Cost of Energy, Net Present Cost, Small-Sized Generation Sources

\section{Introduction}

Typically, demand response (DR) is referred to any program that motivates 
changes in the normal power consumption of the end users (consumers) in response to incentives regarding electricity prices. According to [1], the main objectives of a demand response program are: reduce the periods of peak demand, fill up low-consumption periods (valleys), shift the maximum demand to another period, turn flexible the load curve, and reduce or increase the total consumption.

There are several ways of classifying DR programs. One of them depends on the objectives set [2] in the program; the type of market established (whole sale and retail markets) [3] is another way to classify DRs, and finally DRs can be classified according to the type of resources used [4]. Nevertheless, the two more traditional incentive DR programs are: incentive-based programs to reduce the consumption, and price-based programs [5], [6].

Incentive-based programs aim to reduce the end-user demand by controlling his/her major domestic loads' associated consumption (e.g. cutting air conditioners, electric heaters, etc.). Price-based programs, in turn, strive in lowering the customer demand through the change in prices.

According to [7], one of the countries that showed a high invest in demand-response projects is the USA. Other countries with substantial growth in DR programs are Australia, New Zealand, South Korea, China and Japan.

Despite the existence of a legal framework that allows the use of DR programs, only in some European countries the consumer response is commercially active [8]. According to a survey conducted by SEDC (Smart Energy Demand Coalition), France, Ireland, United Kingdom, Belgium, Switzerland and Finland are the countries with more active DR programs [7], [9]. In [10], some simulation tools are applied to analyse the DR of an islanded system considering some load conditions for its economic operation.

Commercial buildings have a large potential to participate in DR programs for reasons, such as, the electricity they consume today is significant, which gives them also a potential to generate onsite power. The load of these buildings is somewhat predictable operating in repeated schedules, thus, making them good candidates for DR programs. To this feature, it can be added the fact that most of them have a centralized control system, which reduces the cost for integrating them in DR programs [11], [12], [13].

Some of the references available on the response of commercial buildings [14], [15], [16], [17] suggest the use of small or medium-sized generation systems based on renewable sources. This is the case of some urban wind turbines [18], which are driven by the relatively stronger winds available on top of the buildings. Solar panels are also placed on the roof of some buildings, on car parking lots as well as in some other specific areas of the building, as long as they do not interfere with the routine activities of the neighbourhood, air navigation, etc.

Today, most of the public buildings have some degree of automation, if not a high degree of intelligence. Examples of these partially automated systems are the lighting system in the corridors of a building with optical sensors that turn on/off the lights according to the users' needs. There are also some other systems 
activated by infrared sensors to control and make an efficient use of water (water sinks) or to smartly operate the main doors of a building to preserve its inner temperature. Other aspects featuring a building as an intelligent one may be the maximum use of natural light instead of electric lamps, reuse of water, etc.

Automation systems such as BAS (Building Automation System), EMGI (Energy Management and Grid Interaction), and the building's information technology system interact each other through communication protocols that may have a centralized or decentralized arrangement.

The main scope of this article is to evaluate the benefits brought by the installation of some local sources of power and observe its impact on some of the economic variables linked to a commercial building, as well as compare its greenhouse gas emissions for the conditions with and without the presence of such a local generation. It will also be evaluated the building's response towards the utility requirements, commonly referred to as Demand Response. By applying tariffs with hourly, and/or contracts with financial incentives, the utility may induce changes in the load curve and improve operational bottlenecks.

\section{Description of the System}

A medium-sized commercial building was considered to develop the technical and economic analysis. The power demand and consumption of such a building ( $2 \mathrm{MW}$ and $560 \mathrm{MWh} / \mathrm{month}$ ) are mainly fed by the utility. The local sources of power also contribute to complete feeding this demand. The installed sources are three wind generators of $50 \mathrm{~kW}$ each (which together generate approximately 54 $\mathrm{MWh} /$ month), a photovoltaic system containing 14 units, each with $250 \mathrm{Wp}$ capacity. Both renewable sources are installed on top of the building. A 0.5 MVA diesel generator and a storage system (batteries) whose capacity is equal to 200 A-h. The latter sources are installed on the ground floor of the building (Figure 1). For this system, the following analyses were conducted:

- Case 1. Supply of power exclusively from the utility.

- Case 2. Power supplied by the utility and by the sources in the building.

- Case 3. Sensitivity analysis of Case 2.

The data and costs presented next were obtained from commercial catalogues and information provided by some manufacturers. The energy and demand (i.e. peak and off-peak) unit tariffs were obtained from a local utility [19]. The currency used here corresponds to American dollars represented by the symbol (\$).

- Cost of the energy supplied by the utility during the peak period (14:00 22:00): $0.10 \$ / \mathrm{kWh}$.

- Cost of the energy supplied by the utility during the off-peak period (22:00 14:00): $0.067 \$ / \mathrm{kWh}$.

- Cost of the contracted demand from the utility during the peak period: 3.97 $\$ / \mathrm{kW}$.

- Cost of the contracted demand from the utility during the off-peak period: $2.48 \$ / \mathrm{kW}$. 


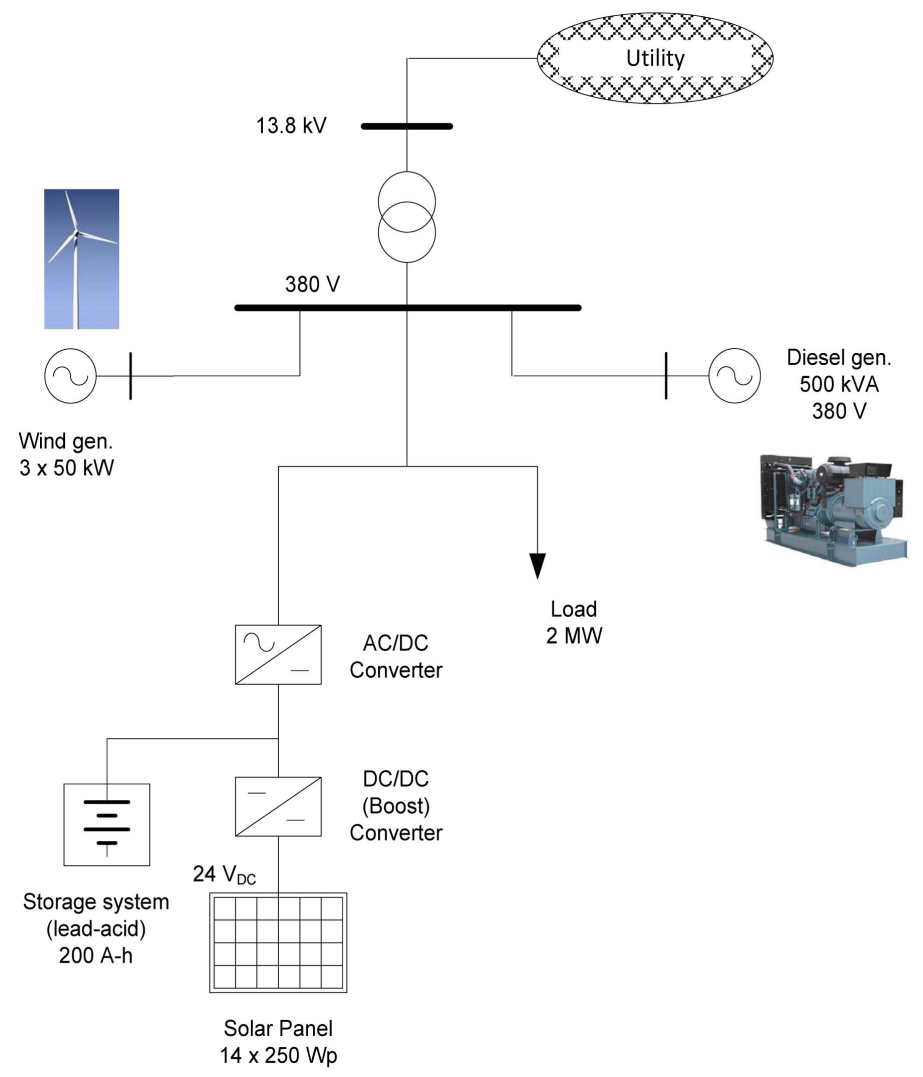

Figure 1. Components of the commercial building used in the analysis.

- Fuel cost (diesel): 0.873 \$/L.

- Diesel generator cost (2018): \$ 40,000 (service period: 15,000 hr).

- Wind generator cost (installation included): \$250,000 (service period: 15 years).

- Converter cost: $\$ 2000$ (service period: 15 years, efficiency $=90 \%$ ).

- Battery bank cost: $\$ 60,000$.

- Cost of solar panels (installation included): \$6000.

- Average annual wind speed: $7.51 \mathrm{~m} / \mathrm{s}$ (top of building).

- Average solar radiation: $4.64 \mathrm{kWh} / \mathrm{m}^{2} /$ day.

- Building coordinates: Latitude: $23^{\circ} 32^{\prime}$ (South); Longitude: $46^{\circ} 38^{\prime}$ (West).

- Annual average temperature: $20.1^{\circ} \mathrm{C}$.

- Annual interest rate: $6 \%$.

\section{Simulation of the Case under Analysis}

The simulations were performed using the HOMER Legacy v2.68 beta program [20], [21]. In Cases 1, 2 and Case 3 (sensitivity analysis) the following variables were analysed:

- Net Present Cost (NPC), which is a well-known method used to assess the viability of a certain project. Succinctly, it results of the difference between the investment value of an asset and the amount that will be redeemed at the end of the investment, brought to present value (\$). 
- Levelized Cost of Energy (LCOE), which refers to the unit net cost due to installation of a power source (renewable or non-renewable) divided by the energy produced over its expected life-time $(\$ / \mathrm{kWh})$.

These variables, together with the $\mathrm{CO}_{2}$ emissions of each of the alternatives analysed are indicators on the building's viability to operate as a partially self-fed building. It will also be evaluated the energy generated by the renewable sources and the diesel generator to compute the cost that this energy represents if sold back to the grid.

\subsection{Supply of Power Exclusively from the Utility (Case 1)}

All the energy is exclusively supplied by the utility (see Table 1). The NPC value is equal to $\$ 4,372,648$. On the other hand, the LCOE (global unit cost of energy) is equal to $\$ 0.100 / \mathrm{kWh}$. The overall operation cost for this case is equal to $\$$. $676,446 /$ year.

The periods of tariff application by the utility along the day are shown in Figure 2. The period of peak tariff is shown in green colour whereas the off-peak period is shown in yellow colour.

\subsection{Power Supplied by the Utility and the Sources within the Building (Case 2)}

Figure 3 corresponds to the simulated system presented in Figure 1. Note that the inclusion of the $\mathrm{dc} / \mathrm{dc}$ converter linking the solar panel to the local generation (shown in Figure 1) is optional. In this case, it was not included.

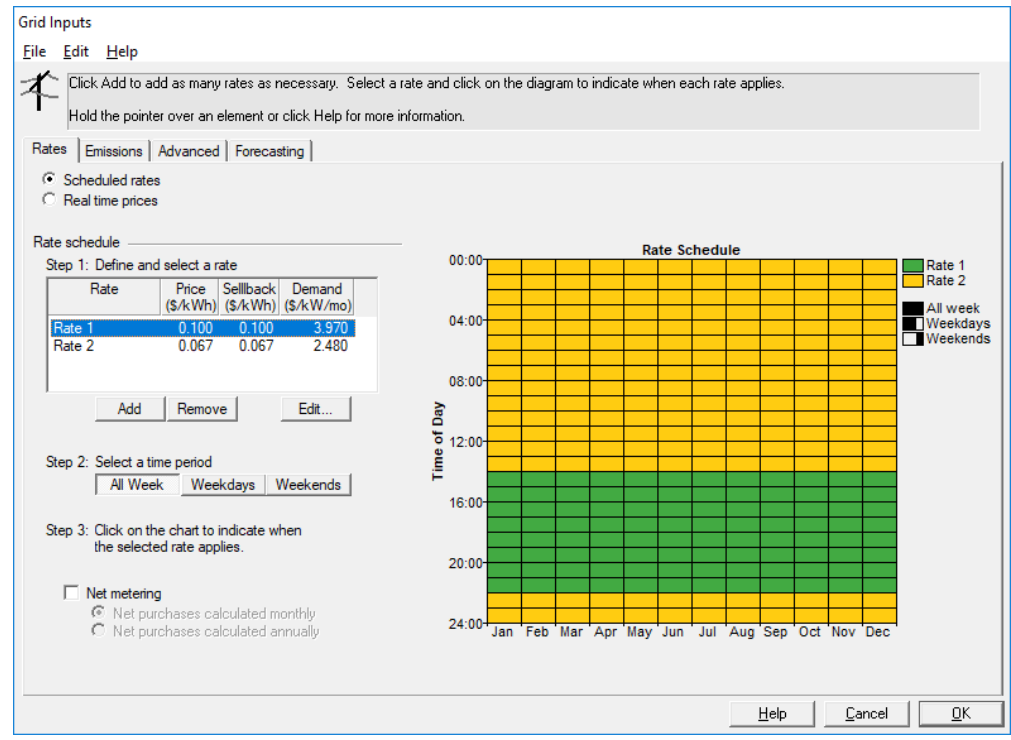

Figure 2. Application of peak (green) and off-peak (yellow) tariffs.

Table 1. Energy purchase from the grid.

\begin{tabular}{ccc}
\hline Component & Production $(\mathrm{kWh} / \mathrm{yr})$ & Fraction $(\%)$ \\
\hline Grid purchase & $6,789,000$ & 100 \\
\hline
\end{tabular}




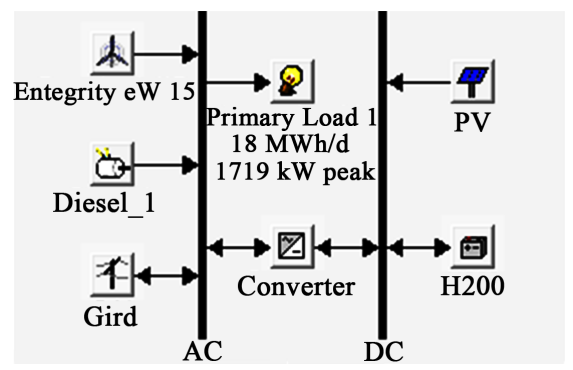

Figure 3. Load fed by the utility and the sources of the building.

Figure 4 shows the daily load curve specified in the simulation tool. It should be noted that (for the sake of comparison) such a load curve will be the same used in all the three analysed cases. Thus, including the load curve of Case 1 and Case 3 would be redundant. The result of this simulation (i.e. Case 2) is shown in Figure 5.

Because the generation sources are relatively small in relation to the demand of the building, the utility will be supplying most of the demanded energy (blue columns). The diesel and wind generators (black and green colours respectively) contribute with less energy. The small PV solar generation (yellow colour), which practically does not appear in the graph, will also be contributing to supply power to the building.

Table 2 shows how the generation of the different components behaves in cumulative terms. In this case, a greater contribution of power production by the utility, followed by the wind and diesel systems, can be observed. Although the diesel generator has a higher capacity than the wind turbine, the software gives priority to the contribution of the renewable sources.

The energy produced by the local sources $\left(E_{L S}\right)$ will be (sum of the first three rows shown in Table 2):

$$
E_{L S}=(4149+688,002+686,493)=1,378,644(\mathrm{kWh} / \mathrm{yr})
$$

The characteristics of each source during the power production is shown in Tables 3-6. For example, Table 3 shows that the PV array has the lowest capacity factor equal to $15.8 \%$ and it also has the least energy contribution to the load $(4000 \mathrm{~kW}-\mathrm{h} / \mathrm{yr})$. This is because its rated power has only $3 \mathrm{~kW}$. The wind generation (Table 4) presents a better scenario with more than $52 \%$ of capacity factor and a much greater annual production (i.e. 688,000 kW/yr), although its rated capacity, compared to the PV array, is also greater ( $150 \mathrm{~kW})$. Due to the issues above explained, mainly the generation cost, the diesel generator presents a low capacity factor (17.4\%) with only $4745 \mathrm{hr} / \mathrm{yr}$ of operation.

The first column in Table 6 shows the global energy purchased from the utility, the second column represents the energy generated by the local sources which will be compensated (i.e. subtracted) from the first column. Thus, the commercial building will only pay the "net" energy purchased shown in the third column. It can also be observed the total (annual) energy and demand charges; the former calculated considering the net purchase of energy. 


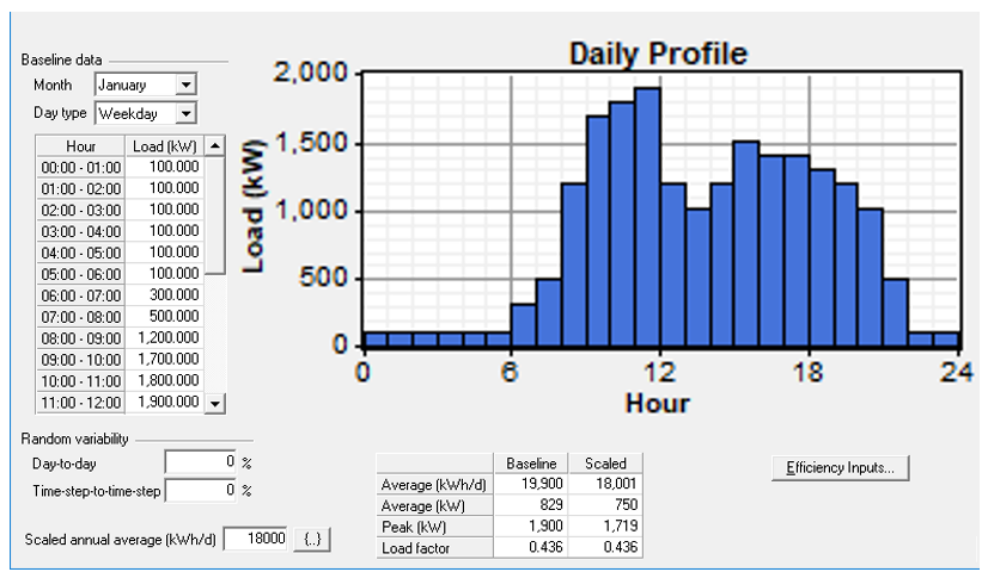

Figure 4. Details of the load curve (Case 2).

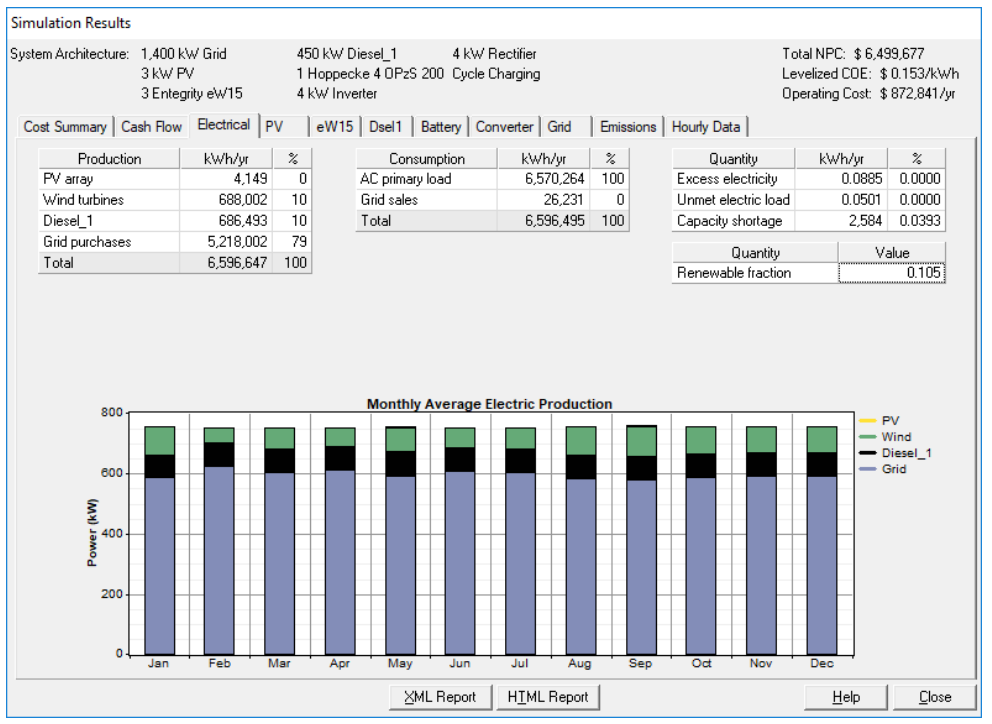

Figure 5. Power supply from the utility and the local sources of the building (Case 2).

Table 2. Participation of the generation components.

\begin{tabular}{ccc}
\hline Component & Production $(\mathrm{kWh} / \mathrm{yr})$ & Fraction $(\%)$ \\
\hline PV array & 4149 & 0 \\
Wind turbines & 688,002 & 10 \\
Diesel_1 & 686,493 & 10 \\
Grid purchase & $5,218,002$ & 79 \\
Total & $6,596,647$ & 100 \\
\hline
\end{tabular}

Table 3. Characteristics of the PV array.

\begin{tabular}{ccc}
\hline Quantity & Value & Units \\
\hline Rated capacity & 3.00 & $\mathrm{~kW}$ \\
Mean output & 0.474 & $\mathrm{~kW}$ \\
Mean output & 11.4 & $\mathrm{kWh} / \mathrm{d}$ \\
Capacity factor & 15.8 & $\%$ \\
Total production & 4149 & $\mathrm{kWh} / \mathrm{yr}$ \\
\hline
\end{tabular}


Table 4. Characteristics of the wind generator.

\begin{tabular}{ccc}
\hline Variable & Value & Units \\
\hline Total rated capacity & 150 & $\mathrm{~kW}$ \\
Mean output & 78.5 & $\mathrm{~kW}$ \\
Capacity factor & 52.4 & $\%$ \\
Total production & 688,002 & $\mathrm{kWh} / \mathrm{yr}$ \\
\hline
\end{tabular}

Table 5. Characteristics of the diesel generator.

\begin{tabular}{ccc}
\hline Quantity & Value & Units \\
\hline Hours of operation & 4745 & $\mathrm{hr} / \mathrm{yr}$ \\
Number of starts & 365 & starts $/ \mathrm{yr}$ \\
Operational life & 3.16 & $\mathrm{yr}$ \\
Capacity factor & 17.4 & $\%$ \\
Fixed generation cost & 34.4 & $\$ / \mathrm{hr}$ \\
Marginal generation cost & 0.218 & $\$ / \mathrm{kWhyr}$ \\
\hline
\end{tabular}

Table 6. Total (annual)energy purchased and sold plus the demand and energy charge.

\begin{tabular}{cccccc}
\hline $\begin{array}{c}\text { Energy } \\
\text { purchased } \\
(\mathrm{kWh})\end{array}$ & $\begin{array}{c}\text { Energy } \\
\text { sold } \\
(\mathrm{kWh})\end{array}$ & $\begin{array}{c}\text { Net } \\
\text { purchases } \\
(\mathrm{kWh})\end{array}$ & $\begin{array}{c}\text { Peak } \\
\text { demand } \\
(\mathrm{kW})\end{array}$ & $\begin{array}{c}\text { Energy } \\
\text { charge } \\
(\$)\end{array}$ & $\begin{array}{c}\text { Demand } \\
\text { charge } \\
(\$)\end{array}$ \\
\hline $5,218,002$ & 26,231 & $5,191,771$ & 1400 & 430,686 & 99,466 \\
\hline
\end{tabular}

The "base case" condition is when the diesel price is equal to $0.873 \mathrm{US} \$ / \mathrm{L}$ and the wind speed equal to $7.51 \mathrm{~m} / \mathrm{s}$. Because these variables are global evaluation factors of the project, the NPC and LCOE variables will also be observed for these conditions.

For this (base case) condition, the NPC $=\$ 6,499,677$; the $\operatorname{LCOE}=0.153$ $\$ / \mathrm{kWh}$, and the cost of operation $=872,841 \$ /$ year.

In Table 7, a comparison of the main economic variables and the $\mathrm{CO}_{2}$ emissions of both cases is presented. Note that Case 2 has got greater values than Case 1; this is due to the capital cost of the generation sources included to which it can be added the price of the fuel.

\subsection{Sensitivity Analysis (Case 3)}

The objective to perform a sensitivity analysis is that in situations where there are hypothetical variables, or variables prone to variations, there will be certain degree of uncertainty in the system, thus, a sensitivity analysis is needed.

During the sensitivity analysis performed in the HOMER program, for any variable used it is inserted a range of values that are believed will vary. Examples of these variables can be, the energy price, fuel price, interest rate, life span of the $\mathrm{PV}$ array, average wind speed, average connected load, etc. Also, it is common to estimate the useful life of equipment and assume that, for example, the price of 
Table 7. Comparison of the main variables between Cases 1 and 2 .

\begin{tabular}{ccccc}
\hline & $\begin{array}{c}\mathrm{NPC} \\
(\mathrm{US} \$ / \mathrm{yr})\end{array}$ & $\begin{array}{c}\mathrm{LCOE} \\
(\mathrm{US} \$ / \mathrm{kWh})\end{array}$ & $\begin{array}{c}\text { Operation } \\
\text { cost } \\
(\mathrm{US} \$ \mathrm{yr})\end{array}$ & $\begin{array}{c}\mathrm{CO}_{2} \\
\mathrm{emissions} \\
(\mathrm{kg} / \mathrm{yr})\end{array}$ \\
\hline Case 1 & $4,372,648$ & 0.10 & 676,446 & $4,290,648$ \\
Case 2 & $6,499,677$ & 0.153 & 872,841 & $4,182,966$ \\
Difference & 2127,029 & 0.053 & 196,395 & 107,682 \\
\hline
\end{tabular}

fuel will not change over this period. There is obviously substantial uncertainty in considering this hypothesis, which might not reflect in a real manner the analysis performed and the project scenario.

The sensitivity analysis was performed for Case 2 (i.e. building fed by the utility and the local sources) for which two additional cases were considered:

- Higher wind speed and lower diesel price.

- Lower wind speed and higher diesel price.

\subsubsection{Sensitivity Considering a Higher Wind Speed and Lower Diesel Price}

A drop in the diesel price to $0.75 \$ / \mathrm{L}$ and an increase in the wind speed $(8.5 \mathrm{~m} / \mathrm{s})$ was in this case applied. In Figure 6 and Figure 7 the behaviour of the base case is represented through the crossed blue lines inside each window. It can be observed that both the NPC and LCOE are highly sensitive to the fuel price (higher slope) and to a lesser extent to the wind speed.

In Table 8, the power production of the different components is shown. Note that an increase in the wind speed makes the wind generator to produce more energy.

The total power produced by the local sources will be:

$$
E_{L S}=(4149+892,810+674,048)=1,571,007(\mathrm{kWh} / \mathrm{yr})
$$

The quantities corresponding to the PV array did not change. This is because it has not been accounted in the sensitivity analysis. The reason is that its installed capacity is relatively small, thus, little change would produce in the whole power production.

The mean output power and the capacity factor of the wind generator are shown in Table 9. In Table 10, the main operative characteristics of the diesel generator are shown.

The energy purchased from the utility and the net energy sold by the building, as well as the demand and energy charges are presented in Table 11.

In this case, due to the lower fuel price the diesel generator operates at a daily basis (i.e. it is more used) operating approximately 50\% (4745/8760) of the time along the year. It was not included the case when simultaneously the wind speed and the fuel price increase as the simulation toll would obviously give priority to the wind generator. 


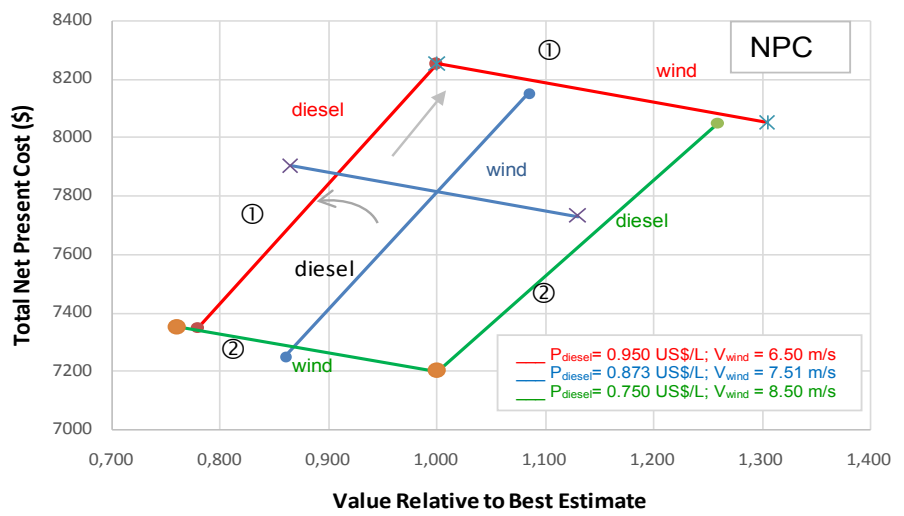

Figure 6. Effect on NPC due to the variation of diesel price and wind speed.

Table 8. Power production of the various sources. Increase in the wind speed.

\begin{tabular}{ccc}
\hline Component & Production $(\mathrm{kWh} / \mathrm{yr})$ & Fraction $(\%)$ \\
\hline PV array & 4149 & $0 \%$ \\
Wind turbines & 892,810 & $13 \%$ \\
Diesel_1 & 674,048 & $10 \%$ \\
Grid purchase & $5,063,325$ & $76 \%$ \\
Total & $6,634,331$ & $100 \%$ \\
\hline
\end{tabular}

Table 9. Characteristics of the wind generator during its operation.

\begin{tabular}{ccc}
\hline Variable & Value & Units \\
\hline Total rated capacity & 150 & $\mathrm{~kW}$ \\
Mean output & 102 & $\mathrm{~kW}$ \\
Capacity factor & 67.9 & $\%$ \\
\hline
\end{tabular}

Table 10. Characteristics of the diesel generator during its operation.

\begin{tabular}{ccc}
\hline Quantity & Value & Units \\
\hline Hours of operation & 4745 & $\mathrm{hr} / \mathrm{yr}$ \\
Number of starts & 365 & starts $/ \mathrm{yr}$ \\
Operational life & 3.16 & $\mathrm{yr}$ \\
Capacity factor & 17.1 & $\%$ \\
Fixed generation cost & 30.0 & $\$ / \mathrm{hr}$ \\
Marginal generation cost & 0.188 & $\$ / \mathrm{kWhyr}$
\end{tabular}

Table 11. Energy purchased and sold by the local sources.

\begin{tabular}{cccccc}
\hline $\begin{array}{c}\text { Energy } \\
\text { purchased } \\
(\mathrm{kWh})\end{array}$ & $\begin{array}{c}\text { Energy } \\
\text { sold } \\
(\mathrm{kWh})\end{array}$ & $\begin{array}{c}\text { Net } \\
\text { purchases } \\
(\mathrm{kWh})\end{array}$ & $\begin{array}{c}\text { Peak } \\
\text { demand } \\
(\mathrm{kW})\end{array}$ & $\begin{array}{c}\text { Energy } \\
\text { charge } \\
(\$)\end{array}$ & $\begin{array}{c}\text { Demand } \\
\text { charge } \\
(\$)\end{array}$ \\
\hline $5,063,325$ & 63,916 & $4,999,409$ & 1400 & 415,536 & 99,046 \\
\hline
\end{tabular}




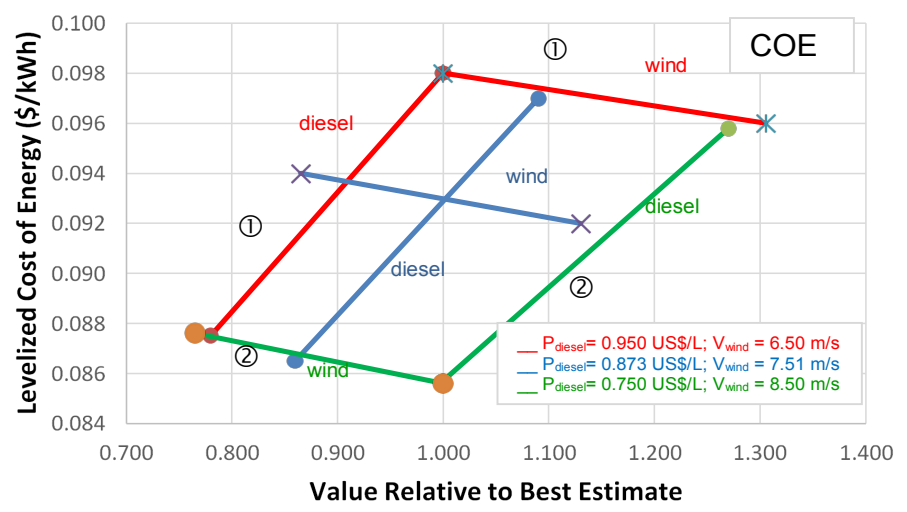

Figure 7. Effect on the unit cost $(\mathrm{COE} \$ / \mathrm{kWh})$ due to the variation of diesel price and wind speed.

\subsubsection{Sensitivity Considering Lower Wind Speed and Higher Diesel Price} Under this condition, a reduction of the wind speed to $6.5 \mathrm{~m} / \mathrm{s}$ and an increase in the diesel price to $0.95 \$ / \mathrm{L}$, occurs. Analogously, the values of the NPC and LCOE relative to the best estimate are also shown in Figure 6 and Figure 7.

In Table 12, it can be observed that due to the increase in fuel price, the diesel generator reduces its power production in relation to the previous case.

The total power produced by the local sources will be (Table 12):

$$
E_{L S}=(4149+468,585+702,214)=1,174,971(\mathrm{kWh} / \mathrm{yr})
$$

Features like the mean output and the capacity factor of the wind generator are shown in Table 13. In Table 14, the main operative characteristics of the diesel generator are shown.

For this case, the energy purchased from the utility and the net energy sold by the building, as well as the demand and energy charges are presented in Table 15.

A synthesis of the total energy produced by the local sources presented in Table 2, Table 8 and Table 12, as well as the $\mathrm{CO}_{2}$ emissions, is presented in Table 16.

The result of the sensitivity analysis considering a drop in the diesel price to $0.75 \$ / \mathrm{L}$ and an increase in the wind speed $(8.5 \mathrm{~m} / \mathrm{s})$ can also be seen in Figure 6 and Figure 7 (green lines). The analysis of these variations will be presented in the next section. Note that with the diesel price becoming higher (i.e. blue line shifted to the left side until it rides the red line) the value relative to the best estimate worsens (decreases) which increases the diesel NPC (1. A similar behaviour occurs in the case of the wind generation NPC.

Conversely, if the diesel price becomes lower (i.e. blue line is shifted to the right side until it rides the green line) the value relative to the best estimate rises (2) decreasing the diesel's NPC. This behaviour also occurs in the case of the wind generation NPC.

A similar behaviour occurs in the case of the LCOE in which the "best estimate value" decreases if the diesel price increases (1). Conversely, this value improves if the diesel price falls (2). 
Table 12. Power production of the various sources. Increase in the diesel price.

\begin{tabular}{ccc}
\hline Component & $\begin{array}{c}\text { Production } \\
(\mathrm{kWh} / \mathrm{yr})\end{array}$ & $\begin{array}{c}\text { Fraction } \\
(\%)\end{array}$ \\
\hline PV array & 4149 & $0 \%$ \\
Wind turbines & 468,585 & $7 \%$ \\
Diesel_1 & 702,214 & $11 \%$ \\
Grid purchase & $5,399,972$ & $82 \%$ \\
Total & $6,574,919$ & $100 \%$ \\
\hline
\end{tabular}

Table 13. Characteristics of the wind generator during its operation.

\begin{tabular}{ccc}
\hline Variable & Value & Units \\
\hline Total rated capacity & 150 & $\mathrm{~kW}$ \\
Mean output & 53.5 & $\mathrm{~kW}$ \\
Capacity factor & 35.7 & $\%$ \\
\hline
\end{tabular}

Table 14. Characteristics of the diesel generator during its operation.

\begin{tabular}{ccc}
\hline Quantity & Value & Units \\
\hline Hours of operation & 4745 & $\mathrm{hr} / \mathrm{yr}$ \\
Number of starts & 365 & starts $/ \mathrm{yr}$ \\
Operational life & 3.16 & $\mathrm{yr}$ \\
Capacity factor & 17.8 & $\%$ \\
Fixed generation cost & 37.2 & $\$ / \mathrm{hr}$ \\
Marginal generation cost & 0.237 & $\$ / \mathrm{kWhyr}$ \\
\hline
\end{tabular}

Table 15. Energy purchased and sold by the local sources.

\begin{tabular}{cccccc}
\hline $\begin{array}{c}\text { Energy purchased } \\
(\mathrm{kWh})\end{array}$ & $\begin{array}{c}\text { Energy sold } \\
(\mathrm{kWh})\end{array}$ & $\begin{array}{c}\text { Net purchases } \\
(\mathrm{kWh})\end{array}$ & $\begin{array}{c}\text { Peak demand } \\
(\mathrm{kW})\end{array}$ & $\begin{array}{c}\text { Energy charge } \\
(\$)\end{array}$ & $\begin{array}{c}\text { Demand charge } \\
(\$)\end{array}$ \\
\hline $5,399,972$ & 4503 & $5,395,468$ & 1400 & 446,763 & 99,724 \\
\hline
\end{tabular}

Table 16. Total energy produced by the local sources in each case (comparison).

\begin{tabular}{ccc}
\hline & $E_{L S}(\mathrm{kWh} / \mathrm{yr})$ & $\mathrm{CO}_{2}$ emissions $(\mathrm{kg} / \mathrm{yr})$ \\
\hline Case 2 (utility + sources) & $1,378,644$ & $4,182,966$ \\
Case 3 (sensitivity 1) & $1,571,007$ & $4,322,052$ \\
Case 3 (sensitivity 2) & $1,174,971$ & $4,053,199$ \\
\hline
\end{tabular}

\section{Commercial Building Participating in Demand Response Programs}

This analysis was conducted considering some hypotheses, namely:

Case 2. (Section 3.2)

If the energy generated by the local sources is injected into the grid by the 
battery during the period 17:00 - 21:00 (peak period), the price at which the energy is sold, according to the spot price (the ratio between the maximum spot price and the peak period price is 1.28$)$, would be $(\mathrm{kWh} / \mathrm{yr}$ taken from Table 16):

$$
C_{\text {sell-back }}=(1,378,644 \mathrm{kWh} / \mathrm{yr} \times 0.1 \$ / \mathrm{kWh} \times 1.28)=176,466 \$ / \mathrm{yr}
$$

This would be the revenue value due to the local sources and could represent approximately $40 \%$ of the building's annual cost (i.e. 176,466/430,686 =0.40). This value is related entirely to the energy cost $(\$ .430,686 / \mathrm{yr})$ presented in $\mathrm{Ta}$ ble 6 . Note that the demand cost is not being considered here.

Indeed, this condition is subject to an agreement reached between the utility and the government to encourage the contribution of end-users.

Case 3. Recall that this case explores two conditions:

1) Section 3.3.1

An increase in the wind speed and a drop in the diesel price was previously established for this case. Thus, by the same philosophy as in Case 2, the sell-back cost will be:

$$
C_{\text {sell-back }}=(1,571,007 \mathrm{kWh} / \mathrm{yr} \times 0.1 \$ / \mathrm{kWh} \times 1.28)=201,089 \$ / \mathrm{yr}
$$

This sell-back value represents approximately $48.4 \%$ of compensating profit in relation to the energy charge presented in Table 11.

2) Section 3.3.2

Analogously, in the second case of sensitivity (i.e. lower wind speed and higher diesel price) the sell-back value will be $\$ 150,396 / y r$, which represents approximately $33.66 \%$ of compensating profit in relation to the energy charge presented in Table 15. Note that the sell-back cost is more sensitive to the wind speed than to the diesel price.

\section{Discussion}

In the above example, the PV source is relatively small. This is because its size is limited by the available area of the building's roof. However, its minor contribution to the analysed costs, together with the contribution of the wind generators, made the difference in relation to Case 1.

Also, since the analysed building requires a relatively high degree of power availability and reliability (i.e. it can be the case of a shopping mall) a diesel genset was included. The impact of its acquisition and operational costs was partly offset by the renewable sources that have a null fuel cost.

In some countries, the application of the microgrid technology and the smart building technology is currently leveraged by some government incentives in the electric sector. This is the case of the Brazilian ProGD (Program for the Development of Distributed Generation) whose aim is to broaden and deepen the actions to stimulate the power generation by the consumers, as long as it is based on renewable sources, especially solar power. Another similar incentive in the country is PROINFA (Program for the Incentive of Alternative Sources) that 
promotes the participation of alternative sources (e.g. wind power, biomass, and small hydropower plants) within the National Interconnected System. Other areas such as the construction and architecture have also some incentives for the construction of smart buildings; however, there is still a relatively long way to run before the application of this technology becomes mandatory to attain significant benefits for the environment.

\section{Conclusions}

Moderate investments in generation sources in a building, in either renewable sources or those based on fossil fuels, may bring revenues proportional to the investment, which, in a medium term (i.e., a period less than the service life of the assets) can become significant.

The overall annual cost of the system (NPC) and LCOE is highly sensitive to the variation of the fuel price and, to a lesser degree, to wind speed variations. Hence, investment in renewable generation sources would be more advantageous for this purpose.

The article shows in a straight manner the procedures and data required (for a specific simulation program) to assess the technical and economic impact of the sources contained in a building. Some features characterizing a building as smart, are described here. Along the research conducted, it was observed the lack of some general guidelines and standards to build up new buildings, or to convert conventional ones into smart structures, this should be the next challenge for the scientific community.

\section{Acknowledgements}

The authors would like to thank the Department of Energy Engineering and Electrical Automation of the University of São Paulo for the chance to carry out this research.

\section{Conflicts of Interest}

The authors declare no conflicts of interest regarding the publication of this paper.

\section{References}

[1] Eid, Ch., Koliou, E., Valles, M., Reneses, J. and Hakvoort, R. (2016) Time-Based Pricing and Electricity Demand Response: Existing Barriers and Next Steps. Utilities Policy, 40, 15-25. https://doi.org/10.1016/j.jup.2016.04.001 https://www.sciencedirect.com/science/article/pii/S0957178716300947

[2] Baboli, P.T., Moghaddam, M.P. and Eghbal, M. (2011) Present Status and Future Trends in Enabling Demand Response Programs. IEEE Power and Energy Society, General Meeting, San Diego, CA, 24-29 July 2011, 1-6. https://doi.org/10.1109/PES.2011.6039608

[3] Wang, F., Xu, H.C., Ti, Xu, T., Li, K.P., Shafie-khah, M. and Catalão, J.P.S. (2017) The Values of Market-Based Demand Response on Improving Power System Reliability under Extreme Circumstances. Applied Energy, 193, 220-231. 
https://www.sciencedirect.com/science/article/pii/S0306261917300971

[4] Hopkins, A.S. and Whited, M. (2017) Best Practices in Utility Demand Response Programs.

http://www.synapse-energy.com/project/best-practices-utility-demand-response-pr ograms

[5] Albadi, M.H. and E1-Saadany, E.F. (2007) Demand Response in Electricity Markets: An Overview. IEEE Power Engineering Society, General Meeting, Tampa, FL, 24-28 June 2007, 1-5. https://doi.org/10.1109/PES.2007.385728

[6] Mohajeryami, S., Moghaddam, I.N., Doostan, M., Vatani, B. and Peter Schwarz, P. (2016) A Novel Economic Model for Price-Based Demand Response. Electric Power Systems Research, 135, 1-9. https://doi.org/10.1016/j.epsr.2016.03.026

[7] Faria, P., Spinola, J. and Vale, Z. (2017) Identified Short and Real-Time Demand Response Opportunities in the Corresponding Requirements and Concise Systematization of the Conceived and Develop. Dram GO, Horizon 2020, European Commission. 41. http://dream-go.ipp.pt/PDF/DREAM-GO_Deliverable2.1.pdf

[8] European Commission DG Energy (2016) Impact Assessment Study on Downstream Flexibility, Price Flexibility, Demand Response \& Smart Metering. Final Report, Belgium.

https://ec.europa.eu/energy/en/studies/impact-assessment-study-downstream-flexib ility-price-flexibility-demand-response-smart

[9] Smart Energy Demand Coalition-SEDC (2017) Explicit Demand Response in Europe, Mapping the Markets 2017. Brussels, Abril.

http://www.smarten.eu/wp-content/uploads/2017/04/SEDC-Explicit-Demand-Resp onse-in-Europe-Mapping-the-Markets-2017.pdf

[10] Neves, D., Pina, A. and Silva, C.A. (2015) Demand Response Modeling: A Comparison between Tools. Applied Energy, 146, 288-297.

https://doi.org/10.1016/j.apenergy.2015.02.057

[11] Watson, D.S., Kiliccote, S., Motegi, N.M. and Piette, M.A. (2006) Strategies for Demand Response in Commercial Buildings. Proceedings of the 2006 ACEEE Summer Study on Energy Efficiency in Buildings, Pacific Grove, CA, 13-18 August 2006, 1-14.

[12] Mutule, A., Obushev, A., Grebesh, E. and Lvovs, A. (2017) Feasibility Study for Demand Response in Commercial Buildings. Proceedings of the $9^{\text {th }}$ International Scientific Symposium on Electrical Power Engineering, Slovakia, StaráLesná, 12-14 September 2017, 1-7.

[13] Kjaergaard, T., Arendt, M.B., Clausen, K., Johansen, A., Jradi, A., Jorgensen, M. and Wollsen, B.N. (2016) Demand Response in Commercial Buildings with an Assessable Impact on Occupant Comfort. 2016 IEEE International Conference on Smart Grid Communications, Sydney, NSW, 6-9 November 2016, 1-6.

[14] Bobrova, D. (2015) Building-Integrated Wind Turbines in the Aspect of Architectural Shaping. Procedia Engineering, 117, 404-410.

https://doi.org/10.1016/j.proeng.2015.08.185

[15] The Council on Tall Buildings and Urban Habitat, Al Bahar Towers, Abu Dhabi. https://freshome.com/2012/12/24/intelligent-shading-system-showcased-by-abu-dh abis-al-bahar-towers/

[16] Wurtz, F. and Delinchant, B. (2017) Smart Buildings Integrated in Smart Grids: A Key Challenge for the Energy Transition by Using Physical Models and Optimization with a Human-in-the-Loop Approach. Comptes Rendus Physique, 18, 428-444. https://doi.org/10.1016/j.crhy.2017.09.007 
[17] Kaygusuz, A., Keles, C., Alagoz, B.B. and Karabiber, A. (2013) Renewable Energy Integration for Smart Sites. Journal of Energy and Buildings, 64, 456-462. https://doi.org/10.1016/j.enbuild.2013.05.031

[18] ClimateTechWiki, Wind Energy: Building-Integrated Turbines, 2018. http://www.climatetechwiki.org/technology/building-integrated-wind-turbines

[19] AES Eletropaulo (2018) Electric Energy Tariff. https://www.aeseletropaulo.com.br

[20] HOMER Energy LLC Program, Legacy v2.68 Beta. http://www.homerenergy.com/

[21] Givler, T. and Lilienthal, P. (2005) Using HOMER ' Software, NREL's Micropower Optimization Model to Explore the Role of Gen-Sets in Small Solar Power Systems. Case Study: Sri Lanka. Technical Report, NREL/TP-710-36774.

https://www.nrel.gov/docs/fy05osti/36774.pdf 